\title{
MODERNISM IN PERSIAN PAINTING AND STUDYING CUBISM ART STYLE IN THE ART WORKS OF THIS ERA
}

\author{
Faranak BASIRI \\ Alzahra University, Iran \\ faranakbasiri123123@gmail.com \\ Ashrafosadat MOUSAVILAR \\ Alzahra University, Iran
}

\begin{abstract}
The modern painting of Iran can be considered as one of the most significant art trends in the history of Iran as well as a period of transition, change and painting creative work. One of the clear changes in the paintings of this era is the growing trend toward modern European art styles and the manner of making relationship with European styles. Although at times Persian artists have merely imitated the western artists, this movement is not depriving of precious art work. This study investigates on the modern Persian painting and cubism art style in Ziapour Art works. Considering the aim of the research, this is a fundamental research and with regard to the nature of the research, it is a historical, descriptive and analytical research. The results show that the creative method applied by Ziapour at creation of his new art style is an instance of creative misreading proposed by Bloom. He has tried not to be affected by the dominance of the cubism art style and has invented a new creative method to create art works by flexibility at the style, theme, visual elements and principles in order to avoid imitation and influence of cubism style.
\end{abstract}

Keywords: Persian modern art, Ziapour, Cubism style

\section{INTRODUCTION}

The art works are the manifestation of the activities of the artists who have contributed to create beautiful and creative art work. Mere skill and mastery of the artist is not sufficient for creating an art work, but it is in need of a kind of creativity in order to be timeless and everlasting. The advances in technology and the emergence of Modernism as a new phenomenon in human life, has made drastic changes in life style, thoughts and effective trends. No aspect of the human life was immune to storms of the modern life elements. This new phenomenon even affected the politics, society and art (Godarzi, 2005).

The modern painting of Iran can be considered as one of the most significant art trends in the history of Iran and as an era of transition, change and the creative work. Modern painting of Iran has had a decisive effect on contemporary Persian art. One of the tangible changes in the paintings of this era is the trend toward modern European art styles and how they deal with European styles. Although at times Persian artists have just imitated the western artists, it occasionally resulted in creation of some precious and everlasting art works which are the hallmark of Persian modern art and resulted in universal reputation of Persian art.

Within an era that was characterized by trend to modernity, the modern artist of Iran has created some art works by utilizing acquired techniques from the west art style. These works were based on national traditions and preserving cultural identity but have been created by new styles (Moghbali et al, 2014). Modern painting is new to Iran, since early on in its formation, modern painting has always been accompanied by many social changes which were the result of the conflict between modernity and traditions. On the one hand, Iran society tries to get in line with criteria of the contemporary world; on the 
other hand, it is involved with past traditions and culture. So, this is a paper that seeks to carry out investigation and research on the modern aspect of the painting. This paper aims to investigate the cubism art style and to analyze its effect on the artist's works. No matter whether these works' quality is high or law, they represent the attempt of the artists who want to come in line with modern world and they need to preserve their Persian identity of their art works as well.

\section{METHODOLOGY}

It is the method applied in research that makes a research reliable, the aim of the research may not be achieved, unless we apply a coherent research methodology. Considering the aim of the research, this is a fundamental research and with regard to the nature of the research, it is historical, descriptive and analytical research.

\section{Painting in Persian culture}

Painting is the very first confrontation of the primitive human being with the art. And it is among the earliest kind of the art that has been survived up to now. Imagination, mentality and displaying and recording what is going on the soul and mind of the human being is common to all human being and every corner of the world (no matter in the west or east). What matters here, is the condition for its improvement and enhancement that makes it a cultural index over the various historical eras.

One of the distinguishing features of the Persian painting is the imagination and daydreaming. Persian painting is the manifestation of a variety of aspects of God. This is true about both ancient era and Islamic era of the nation. Although after the Islamic era, it takes on a mystic significance. The God has long been an in inseparable component in the imaginations of an Iranian artist. So, that is due to this fact that, everything is mythical or imaginary from an Iranian artist point of view and the nature is depicted as s/he remembers it (Pakbaz, 2000).

\section{Establishment of the Persian modern art}

Modernism is in conflict with traditions in all aspects and fields. It has overthrown its preceding system and has founded a new perspective and viewpoint based on the new era. The emergence of the Persian modern art is also the result of modernism. Modernism generated from the western countries and spread on various regions of the world over time and made fundamental changes in its domain of influence. The tendency of Iranian artists toward European art began to exist late Safavid Era. This may be due to the presence of the European artists and their art works in the Safavid court (Maghbali et al, 2014). Kamalolmolk passed away in 1940, and according to some historians his school began to fade away in this year and new movements began to emerge in the contemporary painting of Iran (Godarzi, 2001).

The emergence of modernism movement of Iran dates back to the establishment of the faculty of fine arts (1938). Development of the Modernism in Persian art is somehow related to the effects of the rapid process of modernization on socio-cultural and political fields. The faculty of fine arts played a crucial role in developing the modernism. One of the factors that played a crucial role in modernism development was the establishment of the said faculty that was built in the first university of Iran, and motivated artist to adopt modern European art by way of educational programs and following exhibition. This faculty was the fountainhead of modern art of Iran in the following decades.

University of Tehran was established in 1934 to promote modernism both culturally and scientifically. It played as the only major center for realizing the modernization policy made by Rezashah. In fact, educational policy of the government and university curriculum were at the core of this official project. Modern educational policy was continuously implemented according to this political project. Like other faculties of the University of Tehran, the faculty of fine arts was formed by integrating several institutions in 1940, based on a project proposed by Ismaeil Meraat. Earlier, he had been student in France and had been interested in faculty of arts at "ecole superieure de bouzareah" university. He integrated the school 
of industry, occupation and art with higher school of architecture and established the faculty of fine arts (KeshmirShekan, 2015).

After establishing the faculty, two schools were closed and the professors and amenities of the two schools were assigned to the new art faculty. So, the modern painting has established to replace the preceding art trends but not to coexist with them. But this goal did not realize at once, and the formal stabilization of Iran's modern painting had to prolong by the late 1940s.

Art school of Fine arts, or later Faculty of fine arts, can be called as the most important base for modernism in Iran. When the art students of the faculty graduated and some other students who were in Europe for higher education returned to their hometown, the modernism movement entered into a new stage. Many modern art centers and associations (like associations, galleries, art groups) were created and some other activities like holding the exhibitions ,Biennials, conferences and seminars as well as art books, articles and interviews were published by the press and stabilized the modernism in the art society of Iran(Moghbali et al, 2014).

\section{Cubism style}

Between the 1425 and 1450, the artists all over the Europe left the mediaeval method of displaying the reality which was by way of empirical perceptions. Instead, they relied on visual perception, one-point perspective and natural light. In other word, the artist of the renaissance era ignored to depict the comprehensive truth of the reality that is not foreign to human mind and just depict what is observable by the eyes. For about 450 years, European artists followed the same general principle. Finally, when artist used up all pictorial techniques and possibilities of this style, the cubism was invented to replace it. Cubism style was born in Paris between 1906 and 1908. Within 4 years, visual techniques and technical innovation of this style attracted the other artists in France, Germany, Netherlands, Italy, Czechoslovakia, Russia, America and England.

Cubism somehow affected all technical experiences and stylistic innovation between 1909 and 1914, i.e. all advances of the western avant-garde art. The influence of the cubism was considerably decreased after 1952 , but it affected the pictorial techniques of the many great artists. It proved to be most powerful stimulating factor of the 20 century and has managed to change the impression of the artists from pictorial display techniques and possibilities (Kouper, 1987).

By formulating a logical system in the art, cubist tried to realize the concept of relativeness of the fact that phenomena are intermingled and aspects of the world mutually affect each other. Philosophical nature of this discovery was in line with other discoveries invented by the scientists, especially by the physicians (Pakbaz, 2004).

The exact date of cubism emergence has always been the matter of controversy among the art historians. Some believe that the famous painting "Les Demoiselles d'Avignon" created by the Pablo Picasso is the first sample of emergence of the cubism. This painting depicts women with figures composed of flat, splintered planes and jagged shards and forms which were inspired by African masks. At the bottom of this art work, a piece of magnified dead nature like the dead nature art works created by Cézanne. This painting marks the birth of a new pictorial technique, by which, Picasso has drastically violated the traditional and prevalent principle. Some other art historians believe Paul Cézanne, the French artist's art works' influences on Picasso and Braque was the most significant reason of Cubism movement formation. The technique applied by Cézanne indicates his high interest in geometrical shapes, but his most revolutionary invention as a painter is how he deals with space and his personal imagination of the space. Cézanne left the common linear perspective behind and gave preference to color in creating and stimulating a sense of space. 
In a series of paintings which were designated to "Saint Victoria Peak", Cézanne has used the pink, beige and tan color in the foreground and blue and grey colors in the background. One of these two color spectrums is cool and the other is warm color. They were applied extensively by the early painters of the cubism art style. Cézanne died in 1906 and a great exhibition was held to show his art works. This exhibition played vital role in emerging the cubism.

Such innovations were of significance for the cubist due to two reasons: firstly: this style challenged the physical experiences law, secondly: it motivated the artists to change their view toward painting and view it as an independent integrity (even against) the physical experiences of the outside world which have an independent nature and internal logic.

Therefore, Braque and Picasso, inspired by Cézanne style Cézanne style in the painting, created some art works from the natural landscapes. They exhibit their art works in exhibition in Paris in 1908. The critics criticized this exhibition harshly like that of the first impressionistic works exhibitions. It was in the same exhibition that, the famous critic Louis Vauxcelles coined the term "cubism" to make fun of the new style, the word "cubism" originates from the word "cube". "According to Matisse, he used the term to make fun of the tiny cubes of the Braque, but he admitted the new style after a while" (Pakbaz, 2004). The genuine cubism was initiated by the Braque, Picasso and later Juan Gris. Braque, Picasso and later Juan Gris are the artists who applied this style in unsystematic and genuine way.

\section{The principled of the cubism art style}

The cubists try to present the integrity of a phenomenon (various aspects of an object) on a twodimensional surface at the same time. In this respect, cubism was the rival of the conceptual realism, but not visual and impressionistic realism. They also tried to represent their mentality on the creatures and objects in the form on the geometrical shapes. So, we don't see the reality in this works as we see it in the outside world by our eyes.

Cubism is the product of rational attitude toward the universe. It reacted against the trend which connected Delacroix romanticism, sensorial attraction of the impressionism and painterly qualities and strong color of the Fauvism. He tends to the rational and classic traditions of the Ingres. The pioneers of the cubism left the historical, emotional and sensorial themes and mainly concentrated on the still life as their painting's subjects. In this field, they depicted the combination of the geometrical shapes and objects, and avoided emotional and personal impressions from the objects. They omitted the representation of the space, light and color attraction from their paintings, as an achievement of the impressionists, and virtually painted in mono chrome. By applying the geometrical shape, they ignored the organized lines and the emotional motivations of the subject or painting were considered to be dependent on their rational goal. In a space with low depth, they showed the volume and objectivity of the picture, without using the Three-dimensional view techniques. Unlike the preceding artists, cubists didn't represent the visible world in a way that a landscape of the objects to be visualized in certain time or place. They believe that they should ignore the superficial aspect and consider the internal aspect. In order to represent multi-dimensional object, it requires depicting various angles at the same time i.e. the all possible representation of an object should be visualized. But achieving this goal was impossible virtually. So, at most, the cubist artist was able to utilize just a portion of the unlimited possibilities. The technique used by a cubist artist, was to dissolve and disintegrate the face of the objects into geometrical planes and then compose these flats into an intermingled set. So, the cubist artist claimed to be realistic. But it was conceptual realism rather than visual realism (Pakbaz, 2004).

\section{Types of cubism}

We can divide the cubism into the following subcategories:

"Cézannian cubism"(1907-1919): the subjects were depicted with simple geometrical shapes and with limited colors. This era is characterized by experiences based on later works of the Cézanne and African 
and Iberian sculptures. This era ends when the "Les Demoiselles d'Avignon" painting created by Picasso was finished (early 1907). The structure of this painting bears is the sign of the emergence of the Cubism era. Because we can see the displacement and intermingled plans, concurrent integration of the side view and front view and a kind of two dimensional space (fig.1) (Pakbaz, 2004).

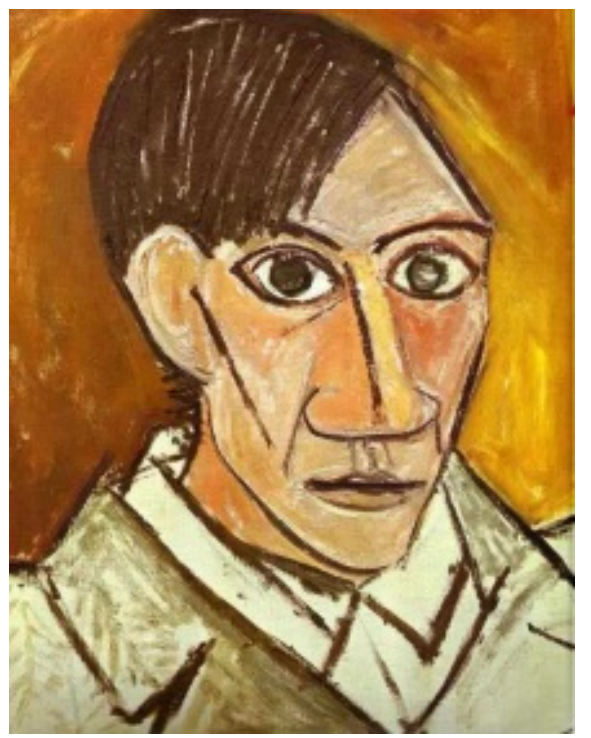

Image1. Pablo Picasso, self-portrait 1907 (www.artexpertswebsite.com)

2. Analytical cubism (1909-1912): the artist draws the pictures in the geometrical shapes and tries to represent various angles of the painting; the color importance takes on the least significance. The art works are mainly drawn in mono- chromic with hues of grey, blue and brown.

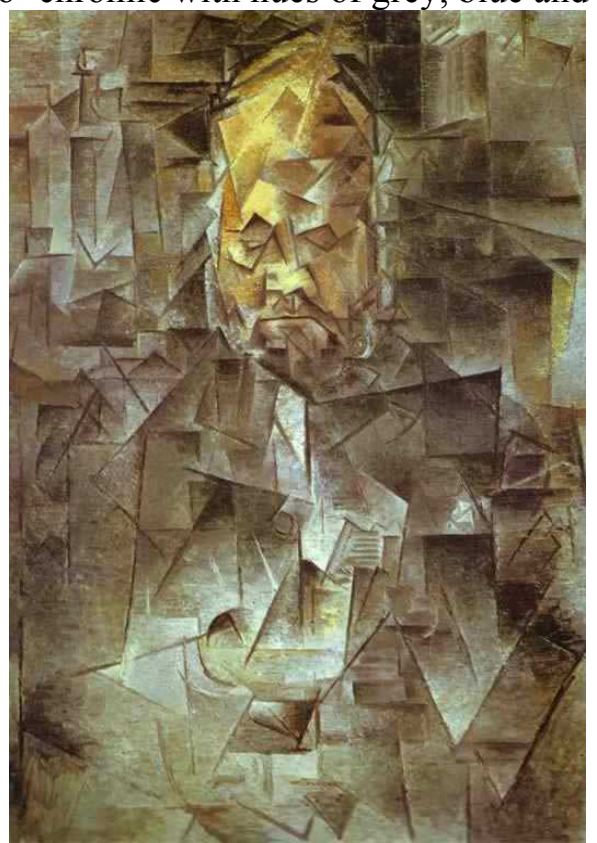

Image 2. Pablo Picasso, Portrait of Ambroise Vollard, 1910 (www.artexpertswebsite.com)

3. Synthetic cubism "Collage" (1913-1914): in this period, Picasso and Braque invented the Papier Colles style (collage) and proposed a new synthetic style from the cubism. They attach the useless objects like 
paper, newspaper and sands into the plane. This assemblage of irrelevant objects was known as collage. The objects which are arranged beside each other, will recover their useful identity, when they take on a formal, abstract application as a part of the art composition (Cooper, 1987).

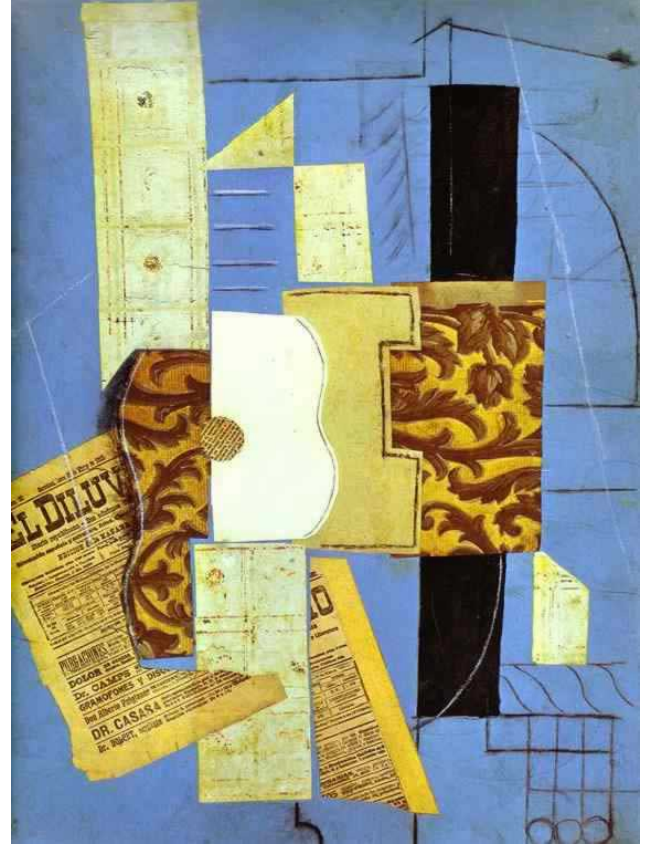

Image 3. Pablo Picasso, Guitar, 1913 (www.artexpertswebsite.com)

Cubism and modern Persian painting

From among the young painters who graduated from the faculty of fine arts, Jalil Rezapour had the highest effect on rejection of the stabilized art systems and promoting new painting styles in Iran. Rezapour had managed to win an scholarship to study his higher education in the France, after coming back to Iran in 1948, he along with Gholam Hossein Gharib and Hassan Shirvani established an association called "Khorous Jangi"(fighting cock) and published a magazine with the same name, Gholam Hossein Gharib and Hassan Shirvani had creative ideas on story writing and theatre.

This association attacked the literature and art that were prevalent on that period. Ziapour were in love with cubism and geometrical painting, he tried to make an Iranian interpretation from the cubism and encourage Persian painters to move toward modernism by getting inspiration from the national art. In a lecture delivered in 2005, Ziapour said "geometrical painting was not foreign to Iran, when this art work lifetime was 40 years in Europe; this style had been for 6000 years in Iran. We always walk on our diverse carpets and never contemplate who has created these design" (Ziapour, 2005).

Ziapour had concentrated on a quisi cubism style at the beginning to learn the integration of some local subjects. But as Rouin Pakbaz states, Ziapour works' didn't represent what cubism reminds. "Because his art lacked some elements of the cubism" However, it seems that Ziapour intention was to create a connection between cubism and traditional Persian art. The result gain from this period is considered to be a form of inconsistency and doubt. Ziapour after doing hard art activities found out this inconsistency and created a personal figurative style. In this style, the reality was shown by integrating Qajar period art and cubism. Ziapour had learned this technique from his teacher, Andre Lhote. Using saturated colors like red; brown is the sign of Ziapour art works in this period. Ziapour selects some square geometrical units from the tiling and native arts as a primary constituent part of the configuration. He forms the structure of his paintings within these dynamic colorful structures. His information and knowledge about the traditional Persian life, rural people and nomadic tribes has been collected by carrying field research in 
these territories. This information provided him an incentive to select these subjects (Keshmirshekan, 2015).

These paintings had been created by angled broken lines in the text of the background of the squares. It was the realization of the suggestions proposed by him since 1948 to change the modern painting style based on the national heritage of the art associations (Mojabi, 1997).

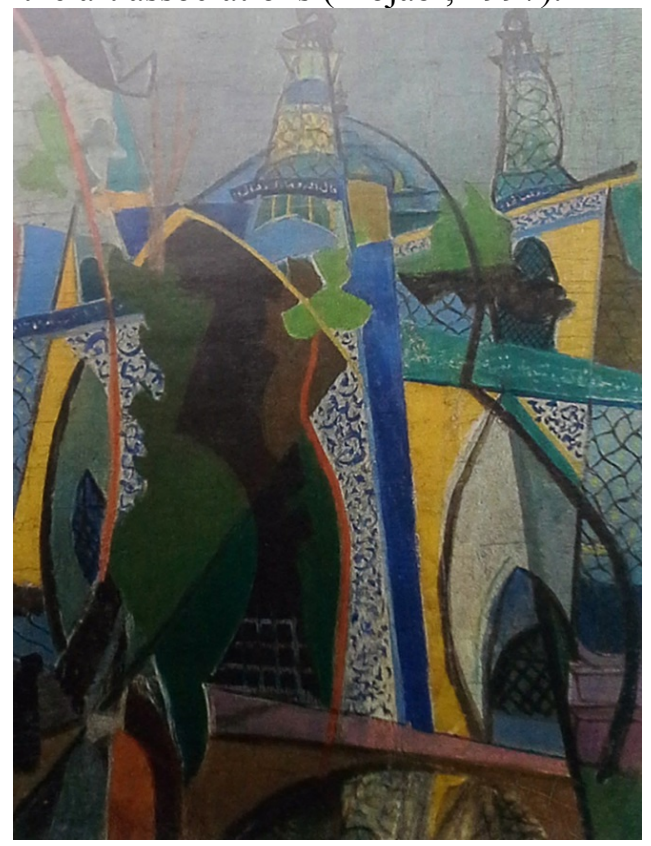

Image 4. "The minaret of the mosque "Painting, Jalil Ziapour, abstract cubism, oil on canvas, $85 \times 61 \mathrm{~cm}$. 1949, museum of contemporary arts, Tehran

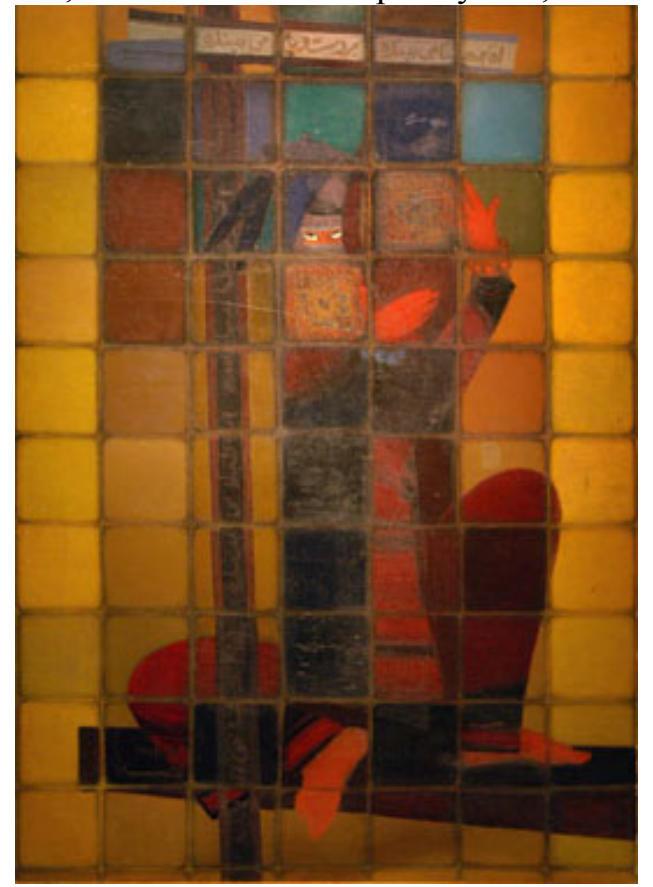

Image 5. "My father puts henna on his hand" painting, Jalil Ziapour, personal and national style, oil on canvas, $121^{\times} 171 \mathrm{~cm} .1965$, museum of contemporary arts, Tehran 
Ziapour writes on this subject: "I wanted to enter our national identity into a modern world by drawing inspiration from our heritage, without being mere imitator or letting them to be imitators. This movement was purposeful and fundamental movement, not a subjective matter".

Zeynab Khatun is one of the most important art works of the Ziapour by using the cubism art style. We will discuss this art work in the following sections.

The structure and geometry of this art work is in the form of a mosaic, the figure of a woman has been depicted on its center. This woman has occupied the whole space of the painting. The figure has been painted with exaggeration, she is sitting and arranging her hairs and holds a turquoise comb in her hand and she has dyed her hair red with henna which has intertextulity with an old poem's hemistich (there need to be turquoise comb). Nudity of her body is covered by dark brawn color. This is a style to show subjects that were not common in Iranian painting. Iranian painter's treatment was different from the European with this regard. The volume and voluminous body has shown by brown color tonality. At the background of the painting, the transcript of the poem has been written at the bottom and top of the painting within two blue stripes, in which there are horizontal and diagonal boxes in white.

The yellow color of the tiles, the dark brown color of the Zinab Khatun and the orange color of the palms and under surface of the feet present a live space for the audience. Generally, integration of the words with the color of the painting and the tile shape of the portrait create such harmony that any static and stillness flee from the mind of audience. The yellow surface behind the figure is surrounded by square shaped shapes in blue tonalities. Therefore, warm colors beside the cool colors has shown a new manifestation of the two dimensional space. In Zeynab Khatun painting created late 1950; Ziapour has chosen a familiar Iranian subject. A woman who is combing her hair (based on a local childish poem), the whole plane of the painting is covered by flat tiles of the same dimensions. Ziapour has depicted the diagonal stripes on which the poems has been written in light blue color to avoid monotony. Some tiles are in blue and some others in in blue-green.in order to represent the twisted figure of Zeynab Khatun, the neighboring tiles are in yellow. The dark and mysterious figure of the Zeynab Khatun with its curved lines controls the painting in all dimensions (Keshmirshekan, 2011).

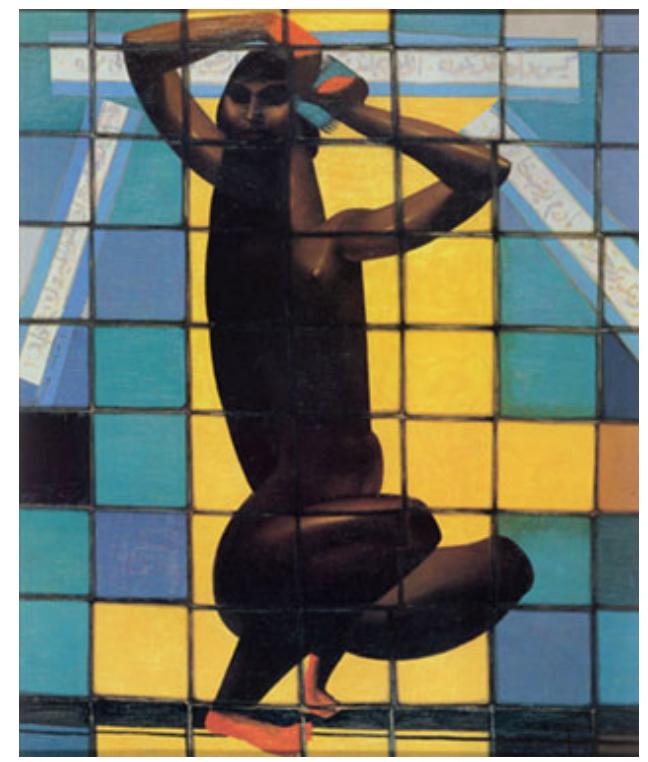

Image 6. The portrait of Zeynab khatun, oil painting on the panel, with the dimensions $95 \times 120 \mathrm{~cm}$ painted by Jalil Ziapour, contemporary visual art museum collections, Tehran (Goudarzi, 2005) 
Ziapour had created many works by imitating from the Impressionist, surrealism, expressionism and cubism styles prior to creating his own special and national style. He somehow misread the cubism style by creating Zeynab Khatun Painting and left his former style in which he had just imitated the common and prevalent style of his era. After painting Zeynab Khatun, Ziapour painted all of his paintings based on his national and personal style. He intentionally violated the regulations and principles of the cubism style. He has implied the flexibility and deviation from the previous artist's style. "We should preserve our national identity but we should also try to make relationship with world culture. "When I came back to Iran, I was wondering why we don't make use of our numerous possibilities. I had seen how the European deal with their past traditions, how they deal with current situation and how they determine their frame of deviation and how they make the process of changes... my work and duty was to rely on our local culture and find those aspects of our culture that is still alive and conforms to the world paining language. I wanted to develop these aspects and improve the art and culture of my country" (Mojabi, 1997).

Ziapour made use of the capacities of the Persian painting and stood against imitation from cubism. In fact, Ziapour had always been fascinated by cubism and geometrical painting but he has tried to put a Persian interpretation on the cubism and to encourage Iranian painters to draw inspiration from national art and draw their attention toward modernism.

\section{CONCLUSION}

Although it is a widely held view that western painting style was entered into Iran dates back to Shah Abbas, the Safavid king, period, the first sign of modernism in Iran dates back to Qajar dynasty period. It seems that emergence of the modernist movement in Persian art has formed with regard to the necessities and requirements of that period of Iranian culture. The pioneers of Persian modern art managed to make some associations between traditional and basic art of Iran and contemporary art. The trend of the Iranian art (themes, patterns, applying the characteristics and visual qualities) was applied by the modern artist in the new forms. They tried to do their nest they managed to reflect their mental perception of the outside reality by using a new style along with creativity in reflecting their artistic ideas. Following emergence of the modernism in Iran and its subsequent changes, Modern artists' of Iran relied on the their preceding stable artistic traditions and preserved their artistic identity and trends in a new form which were in line with Persian contemporary painting and modern movement. This movement is known as modern painting of Iran. Ziapour was one of the prominent artists who played an effective role in rejecting the established art systems and promoted the new painting styles in Iran.

The results showed creative method applied by Ziapour at creation of his new art style is an instance of creative misreading proposed by Bloom, because he has tried not to be affected by the dominance of the cubism art style. He has attained a new creative method to create art works by deviation from style, theme and visual elements and principles in order to avoid imitation and influence of cubism style. Generally, we may say, the integration of the Persian and western painting resulted in emergence of the modern art of Iran. This phenomenon is considered as modernism proponents overcoming their opponents and it has gained a positive reputation for Persian art on the international scale.

\section{REFERENCES}

Cooper, D (1987). The history of Cubism, translated by Mehdi Keramati, (1st Ed), Tehran: Sa'di book publication.

Goudarzi, M. (2001). Searching for identity in the contemporary Persian painting, (1st Ed), Tehran: Scientific and Cultural Publishing Company.

Goudarzi, M. (2005). History of Persian painting from the beginning to the present, Tehran: Samt publication (1st Ed).

Keshmirshekan, H. (2011). Amidst shadow and light contemporary Iranian art and artist, Hong Kong, Liaonning Creative Press Ltd 
Keshmirshekan, H. (2015). Contemporary Iranian art: origins, new ideas, (1st Ed), Tehran: Cultural Institute of Nazar Publication

Moghbali, A., Golchin, Sh. (2014). Explaining the roots of Iranian modern painting, Chideman, 3(6)

Mojabi Javadi. (1997). Pioneers of the contemporary painting of Iran, the first generation, translated by Karim Emami, (1st Ed). Tehran: Honar Publcation of Iran.

Pakbaz, R. (2000). Iranian paintings from ancient times until Now, Tehran: Narestan publication.

Pakbaz, R. (2004). Encyclopedia of the arts, (4th Ed), Tehran: Farhange Moaser Publication

Ziapour J. (2005). Collection of the research and art lectures - late Professor Jalil Ziapour, edited by Shahin Saber Tehrani, Tehran: Eslimi publication 